\title{
Case Study on the Principal Leaderships utilised in a Hong Kong Special Secondary School Setting in the NSS Educational Reform
}

\author{
Hastings Chim Ho Yeung ${ }^{1, *}$ \\ ${ }^{1}$ University of Bristol, UK \\ *Correspondence: University of Bristol, UK. E-mail: hastings.chim@bristol.ac.uk \\ Received: November 16, 2014 Accepted: January 14, 2015 Published: January 22, 2015 \\ doi:10.5296/ije.v7i1.6630 \\ URL: http://dx.doi.org/10.5296/ije.v7i1.6630
}

\begin{abstract}
The education reform called the New Secondary School Curriculum (NSS) was first launched by the Education Bureau of Hong Kong (EDB) in 2001. The reform was intended for the improvement of all aspects of education for primary and secondary school students. Thus, when such reform is achieved, the stakeholders of education would benefit in terms of achieving globalization. The ultimate goal of NSS is to cultivate a self-regulatory study mode that focuses on learning instead of mono-induction of knowledge. Upon the directions mapped by the EDB, the implementation was established in three phases. The short-term phase (from the periods 2001-2002 to 2005-2006) was prescribed for all schools to formulate and integrate their school-based curricula with the elements, ideologies, and generic skills suggested by the EDB. Subsequently, the second phase (from the periods 20062007 to 2011-2012) was the intermediate stage for facilitating and piloting the NSS curriculum into the secondary school setting. Eventually, the long-term phase (beyond 20112012) was the preliminary evaluative stage that further consolidated the teaching practice to enhance its efficacy and also provided the schools with opportunities to evaluate critically the catalysts and obstacles affecting student learning outcomes because the first batch of graduates should have had their examination results announced by July 2012.
\end{abstract}

Few studies examine the leadership styles of schools who serve students with Special Education Needs (SEN) and Specific Learning Difficulties (SpLD) during the NSS education reform, including the effects of their leadership models. In this essay, the author will first provide a background of the NSS education reform with Burke's four concepts of change: content, context, process, and change participants. Based on NSS and Bush's leadership models, this paper will present the prerequisite of one of the local special secondary schools in Hong Kong (HK), that is, Tung Wah Group of Hospitals (TWGHs) Mr. and Mrs. Kwong Sik Kwan College (KSKC) and how the two principals of KSKC, Principals Chow and Ng, manage the team with their leadership in this education reform. After identifying their leadership type, the author will analyze whether such educational leadership styles are 
applicable to this special school, as well as make suggestions to address the opposition encountered by school seniors.

Aside from being the author of this case analysis, the writer was also one of the middle managers in this school, having been serving in the English Panel for six years, during which time he had experienced the leadership of these two principals. Both leadership styles were proactively deployed to the NSS education reform, although their consequences differed.

Keywords: Principalship, NSS, SEN, Organisational Change

\section{Introduction}

This essay will provide a background of the NSS education reform with Burke's four concepts of change: content, context, process, and change participants. On the basis of NSS and Bush's leadership models, this paper will present the prerequisite of one of the local special secondary schools in Hong Kong (HK), that is, Tung Wah Group of Hospitals (TWGHs) Mr. and Mrs. Kwong Sik Kwan College (KSKC) and to what extent the two principals of KSKC, Principals Chow and Ng, administer the team based on their leadership in this education reform. Upon the identification of their leadership type, the author will analyze whether their educational leadership styles are applicable to this special school, plus make suggestions to address the opposition encountered by school seniors in local and global context.

\section{Theoretical Framework}

To review the entire case study comprehensively, this essay has adopted and integrated the four elements of change from Burke (2008) and the leadership model of Bush (2003) to synthesize an integrated framework. Burke's concepts of change are utilized to investigate how reform itself can be elicited in terms of content, context, and process, as well as the participants of change while a theoretical framework based on Bush's work is vital to categorize the type of leadership model exercised by the two school principals to reflect further how the principal's leadership could significantly affect the implementation of the NSS education reform in a local secondary school setting.

\section{Background Information on NSS Reform}

\subsection{Context of NSS reform}

The development of education in HK occurred in the era of globalization that is advocated by various countries, particularly in the Asia Pacific region (Chan, 2010; Cheng, 2009; Wong, 2009). Therefore, HK should be salient and prominent to consistently be among the most competitive and prestigious cities worldwide, which makes education reform essential. Quong (2011) emphasizes that the internal context can be elucidated in four levels. The 
outermost layer is the macro level, which refers to the reorganization or recreation of the global vision. This level is assimilated by global citizens through the reintegration of the educational system, thus ushering a new trend toward privatization, marketing, and diversification of education. The middle layer is the micro level, which highlights the significance of parental and public participation, as well as the participation of other stakeholders in school operation and leadership. The core refers to dual levels. One is the site-level manifesting pursuit of excellence in education, reliability, and holistic development. Included as well is the repertoire of teachers and school leaders through consistent professional training. Another core is the operation level, which refers to the most updated technology applied in acquisition, teaching, and assessment that can be attributed to the benefits and advantages derived from the Internet and information technology.

External context can be attributed to the progress of China as an influential county in the international arena (Wong, 2009). This condition has resulted in a spontaneous and inarguable revolution in education to nurture global citizens who are triliterate and who possess dual identities as Chinese and British colonists that benefit from numerous political implications. Considering the growing cities in China, HK significantly maintains its prominence as the most competitive city in the country. Therefore, education reform has become mandatory.

\subsection{Content of NSS reform}

In his work, Quong (2011) highlights that the most significant change is the new university entrance examination, called the HK Diploma of Secondary Education (HKDSE). This exam is a combination of the two current examinations: the HK Certificate of Education (HKCEE) and the Advanced Level Examination. Thus, compulsory schooling should be changed from seven to six years, comprising three years of junior secondary education and three more years of senior secondary education (Cheng, 2009). The four core subjects, which have been adopted in the education reform, are Chinese, English, Mathematics, and Liberal Studies. An additional element is school-based assessment (SBA), which also contributes to final marks apart from the major examination. Another new component is that $15 \%$ of the time should be allocated to other learning experiences (OLEs), which comprise moral and civil education, physical and aesthetic education, as well as community services and career-related experiences. Compared with memorization and recitation of knowledge, which were emphasized in the past, the NSS requires student competence to gather, interpret, and analyze data. Given the change of content and the direction of reform, the syllabi of all subjects should be revised to meet the requirement of the NSS curriculum.

\subsection{Process of NSS reform}

To attain the goals established in the NSS reform, teachers and school supervisors should construct and customize their curriculum to establish their learning objectives and repertoire (Cheung, 2011; Quong, 2011). Teachers should equip themselves with versatility and further enhance their teaching skills through different professional trainings and workshops. The principals and frontline teachers should also identify their own strengths, weaknesses, as well as the school's opportunities and threats when adopting the NSS education reform. This 
practice will help avoid ambiguity or ambivalence during implementation. Such process can be achieved through regular meetings and collaborative lesson preparation for the development of teaching materials and resources, during which teachers can discuss and share insights on their teaching strategies and conduct assessments to enhance their competence further.

\subsection{Change recipient of NSS reform}

Different change recipients are actively involved in the NSS educational reform (Chan, 2010; Cheng, 2009). In the lead role, the principal should be flexible to a new mindset by identifying the potentials of both teachers and students and by providing flexibility for them to foster their acquisition skills to adapt to an ever-changing environment. For a comprehensive administration structure, the principal should designate qualified teachers as middle managers to extend the leadership network and to nurture new leaders with appropriate leadership training as well as different programs. Panel heads should simultaneously review their own curricula and verify whether they can fulfill the NSS requirement. Finally, panel heads should provide their panel members the most updated information and engage them in various learning teams according to their expertise. The counseling and guidance heads can organize job-oriented and interpersonal skills training workshops for their graduates to experience future employment after the HKDSE examination or to guide them on their further studies. As frontline teachers, we should change our values of focusing solely on examination results. Instead, we should broaden the learning experience of students as they prepare for the educational reform. Teachers should manage their expectations and reinforce students' self-confidence. As the center of the education reform, students should expose themselves to society by actively participating in school events and public services. To achieve the ultimate goals of NSS reform, students should develop a life-long learning habit of coping with the changing environment rather than a single assessment (Ho, 2010).

\section{Critical Analysis}

\subsection{Background of KSKC}

The KSKC is a local secondary school supervised by a prominent charitable institution, the TWGH, in HK. This institution designates KSKC with a mission to serve the students with SEN and those who are dyslexic. Therefore, KSKC primarily serves approximately 303 students, of which $70 \%$ have SEN, whereas the other $30 \%$ of students are unmotivated or are learners who encountered grievances in primary school. Since 1998, KSKC had been classified as a vocational training school serving mild grade students with limited intelligence. However, KSKC was re-established as a grammar school required to handle the HKCEE as an exit point for F.5 students in 2003. Such measure was later re-adapted for NSS education reform after 2010.

The TWGH Headquarters administers and manages 18 secondary schools of various backgrounds that adopt either English or Chinese as medium of Instruction. KSKC is the 
smallest secondary school in terms of student population and teaching staff. Nonetheless, owing to the designated mission to serve dyslexic students, KSKC accommodates band three students who demonstrate the weakest learning behavior among other member secondary schools. Therefore, KSKC has become the most disadvantaged secondary school in its neighborhood.

\subsection{Resistance encountered during NSS education reform}

Given that KSKC is a vocational training school for mild grade students, the institution is widely recognized by parents. Thus, KSKC accommodates the enrollment of the weakest students. In a cosmopolitan city emphasizing exam results, parents are likely to be skeptical toward school performance. Such is the same for KSKC graduates, although the institution was later re-established as a grammar school for which enrolment required the public DSE exam. Parents were unlikely to choose KSKC unless their children abruptly reach the bottom-line at the lowest band.

External contextual factors affect school operations and policies on educational reform. For instance, the TWGH Headquarters has adopted a rotational mechanism to swap principals among member schools to avoid power centralization. Therefore, teachers encounter difficulties in finding reassurance owing to the intermittent leadership exercised by different principals. Given this prerequisite, from 2010 onwards, a new principal who used to be a vice principal in a band one school was assigned to manage KSKC.

Given the unfamiliarity with the prerequisite of the learning phenomenon of SpLD/SEN students, a huge gap existed between the principal's expectations that examination results would be similar to those in his previous school and the actual situation of KSKC. To enhance school reputation, the principal deployed an exam-oriented approach to achieve the passing rate of the HKDSE, which aimed to attract the attention of more proficient students and to attain prestige from the headquarters rather than to adhere to the precedent ideologies advocated by SEN/SpLD specialists, which specify that students should be nurtured with multisensory intelligence instead of focusing on decoding text as in the traditional classroom. The principal's disappointment results in a gradual paradox comprising the disappointments accumulated by the teaching staff. Such despair has reached a climax during the NSS educational reform.

Another existing impediment is that SEN/SpLD students are unsurprisingly incapable of remaining attentive in class. Such challenge has augmented the difficulties in regular class teaching. The teaching team, composed of almost 35 teachers, is assigned with more administrative duties. For instance, in a normal-scale school, teachers are typically designated with one subject and one committee. Teachers have at least two subjects and four to five committees in KSKC, despite the fact that it is compulsory for all teachers to be assigned as class teachers. This situation gave teachers insufficient time to cope with the behavioral problems of students. 


\subsection{Management skills of the principal}

To obtain in-depth insight into how management models modify differentiated school directions in addressing the NSS education reform, this paper compared the leadership skills between the two principals based on Bush's six major aspects: goals, organizational structure, external environment, leadership model, time management, and utility of resources. Principal Chow's leadership was effective in the period from 2007-2010, which is the first half of the principalship, whereas Principal Ng's leadership was effective in the second half from 2010 to 2013 .

\subsection{Goals}

During his service, Principal Chow adopted the collegial model to seek consensus before major decisions are made on policies via meetings, questionnaires, and votes. As aforementioned, KSKC is supervised by the charity TWGH. Thus, Principal Chow reconciled the school directions with the TWGH belief that every youngster is teachable and should be an asset to the society. Such belief is widely accepted as the central directive for a special education school in the midst of the educational reform. Conversely, Principal $\mathrm{Ng}$ attempted to legitimize all the decisions by using a formal model requiring the support of every middle manager. Principal Ng emphasized the elimination of the title of special education school, and instead focused on catering to learning diversity in curriculum planning. In this regard, he was adopting a top-down subjective model in which school decisions comply with his value in which conflict among committees, panels, and groups occurs. Consequently, his goals became unstable because of the disunion of the directions (Bush, 2003).

\subsection{Organizational structure}

Under the leadership of Principal Chow, the organizational structure focused on cohesion of the horizontal collaboration, provided that the direction toward the NSS reform was generally supported by frontline teachers. Upon such prerequisite, power distance was unapparent but bonded with interconnectivity. By contrast, Principal $\mathrm{Ng}$ forfeited the teachers' rights to express their concerns. The formal model he incorporated relied heavily on the top-down hierarchy, which reduced the functions of middle managers (Jones, Lefoe, Harvey, \& Ryland, 2012). Thus, all the authority on his hands of him came under scrutiny as he was believed to be building up his personal reputation instead of the considering the benefits to SpLD/SEN students.

\subsection{External environment}

In this work, external environment refers to parents' groups, other secondary schools, the government, and the TWGH Headquarters. In this area, both Principals Chow and $\mathrm{Ng}$ adopted the formal mode. The former's interpretation actively responded to various concerns of the stakeholders focusing on the difficulties of the DSE assessments and also tried to balance the needs with the school's actual situation. Simultaneously, the cultural model supports the balance with TWGH core values to drive school operation. By contrast, given the one-sidedness imposed by Principal Ng, KSKC became a closed system, and the voices of other stakeholders were regarded as obstacles that need to be restricted. Therefore, his 
unchallengeable authority did not interact with the external environment, catalyzing the ambivalence between various stakeholders.

\subsection{School leadership}

As Bush indicated, no single leadership style can suffice thoroughly for the school operation. Integrated leaderships should therefore be represented given the complexity of their multiple utilities. Principal Chow collectively adopted several leadership styles, thus reflecting him as a leader with open-mindedness, democracy, charisma but at the same time inefficiency because of the time-worn process to obtain consent from the majority. As mentioned, he adopted collegial leadership to gain the support of panel heads and committee coordinators regarding the incorporation of the NSS curriculum, with which colleagues were generally willing to follow the goals and decisions compromised by the majority. Apart from the collegial model, central values and beliefs rooted in school operations TWGH Headquarters, such as "diligence, frugality, loyalty, and trust," by which Principal Chow exercised his cultural model to persuade the teaching staff to perform their own duties with cultural values prescribed accordingly. To focus on learning and teaching, Principal Chow recognized the needs of SEN/SpLD students. To a certain degrees, he allowed teachers' flexibility and space to rethink the content of the NSS curriculum, including the teaching materials necessary for such spectrum of students within his guidelines.

With the goals recognized by the majority of frontline teachers and the values set by the TWGH Headquarters as well as his personal perseverance in envisioning the necessities of SEN/SplD students, Principal Chow actively engaged his teaching staff to accomplish the goals and to adapt the NSS reform, all of which are achievable and sustainable for school survival. His transformational leadership in this triangulation reassured the teaching staff of the learning outcomes that showed steady and positive progress in accordance with academic reports and data analysis (Leithwood, 2008).

Instead of the top-down orders from an individual, the next step in his transformational leadership was empowering the authority and widening the space for the middle-managers through the distribution of central leadership. Such an act demonstrated his willingness to rely on his subordinates and their expertise and, most importantly, his trust on their devotion to his belief that distributive leadership was supposed to be strongly influential to schools and students when it was widely applied to the school operations (Leithwood, 2008). In return for the teachers' efforts, Principal Chow offered diligent teaching staff incentives such as permanent contracts and promotions to create a promising career. A rewarding work environment stabilized the teachers' morale and reduced the turnover rate of employees.

In contrast to Principal Chow, Principal $\mathrm{Ng}$ adopted other leadership styles, thus demonstrating him as a leader with rigidity, strict compliance, unclear vision and objectives, disengagements, dictatorship, and self-centered mindset but with considerable efficiency in task completion. According to Bush's theories on leadership, we can categorically identify the principal's style as managerial leadership because it fulfills several aspects and specifications. As previously mentioned, the goals and implementation of the school were always pre-determined by the principal. Moreover, few senior teachers did not proactively get 
involved with and interact with frontline teachers and even with middle managers. Nevertheless, the goals and decisions were fairly unclear because teachers seldom explained the rationale behind decisions or in some cases deemed it irrelevant to support such decisions by factual analysis. The principal lacks frontline experience with SEN/SpLD students. One of the main reasons for the principal's leadership style lies in the fact that decision making cannot gain the recognition of frontline teachers. The teachers have generally become critical toward the hidden agenda of the principal, who aims at developing his own reputation through the manifestation of all the additional functions and events, instead of focusing on regular routines for SEN/SpLD students during the education reform. The nature of structure is deemed to be subjective. Based on top-down management strategies, the principal adopted punishments and downsizing acts, ranging from verbal and written warning letters to an open announcement of the faults of teachers. He showed his preference to manage his subordinates with absolute authority by terminating contracts. These measures can be deemed particularly threatening considering the sharp decline of the student population in this decade (Quong, 2011). To sustain a career in such a critical period, the teachers have to endure such a dilemma.

\subsection{Time management}

Bush (2003) states the significance of both formal and ambiguity models, as well as managerial leadership when time was limited for management in considering immediate follow-ups, particularly in the middle of NSS educational reform. Time for discussion had therefore been restricted when Principal Chow requested common consent from every middle manager and frontline teacher regardless whether conflict is between panel heads and committee coordinators. Thus, collegial leadership became an impediment during decision making.

Drawing on the notion of the good efficacy derived by formal leadership and the managerial model, Principal Ng enhanced the smoothness and efficiency for all decisions. However, such model and leadership cannot be sustainable in the long term, given that the frontline teachers might not be eager, or even rebellious, to his policies when their voices were not acknowledged (Walker, 2009).

\subsection{Utility of resources}

As previously mentioned, TWGH is the largest charity in HK. TWGH can provide abundant resources for subordinate schools. Bush specified that collegial leadership could be adopted to distribute the resources rationally when these resources are rather adequate. Principal Chow allocated resources based on the actual needs of different parties. All heads would be invited to attend the budget planning held in the TWGH Headquarters so that they can express their needs and thus receive resources correspondingly. Principal $\mathrm{Ng}$ justified the needs of the different parties by his own analysis and estimation. The adoption of the managerial and formal models could be realized as subjective, but at the same time alleviated the conflict and arguments among various parties owing to the central decisions solely made by Principal Ng. 


\section{Suggestions for Management}

Having highlighted the different features of leadership and managerial models for various situations and contexts, school principals and seniors should not adopt a single or narrow range of leaderships for school operation in the way that such inadequacy signifies the regression and the encapsulation of the leaders from the dynamic area of contemporary NSS reform (Ho, 2010; Jones, 2012; Walker, 2004). The EDB stated that the ultimate rationale of NSS is the nourishment of global citizenship, which is unlikely to be accomplished by a unidirectional management model and leadership style. In fact, as Gronn (2010) suggested, the use of an integrative approach could be deemed more salient.

\subsection{Gronn's integrated approach to management models and leadership styles}

Gronn (2010) initiates a synthesis approach that might serve as reference for the principals and seniors to adopt suitable leadership and managerial models during the NSS education reform. The synthesis approach can be exemplified by a task incorporating the NSS curriculum into the reform. First, in the preliminary stage, the EDB advised the school administrators on how to incorporate the NSS elements into the school-based curricula. To integrate the SEN/SpLD features into the hybrid curriculum, collegial and participative leadership should seek professional advice from the academic committee and the key learning area (KLA) panels. The counseling and discipline committee and educational psychologists can determine how to sustain students' attention in class. Different specialists and experienced teachers are willing to contribute their perspectives and insights. Thus, an initial framework can be formulated. Conflicts and contradictions along this preliminary stage exist and require compromises in terms of goals and learning outcomes owing to the efforts to receive sufficient resources. One of the typical examples is the electives that various KLAs ought to adopt, with which the panel and the members should be given rights and flexibility to decide according to the students' needs. If at this point, common consensus cannot be reached, the principal and the seniors should consider adopting a formal model. Managerial leadership should settle different views. Such should be the least preferred strategy considering that opinions and expertise should always be acknowledged.

Apart from different exclusive reflections upon the policies, the participants may interpret the policies based on their own perceptions. The school principal should approach the individuals, listen to their voices, and address their needs, as well as consider their practice. In short, decision makers can unify school directions with their own interest for their compliance. For example, the English panel head and the extracurricular activities committee might plan to include excursions, visits, English drama, and debate as OLEs. Subsequently, the school principal can negotiate and investigate the proposal's feasibility. Once a compromise has been reached, the principal and the panel head, as well as the frontline teachers, should comply with their agreement. The principal in this aspect should indicate that the school-based policies are always characterized by individualistic elements, in which the frontline teachers should always be convinced and respected instead of being mandated by top-down decisions. 
Both the internal and external contexts are ever-changing. Uncertainty, ambivalence, and ambiguity are taken for granted during the implementation of the NSS educational reform. Hence, flexibility and adjustment should address smooth flow and general participation. Leaders are supposed to deal with discrepancies in readiness and strategies with the ambiguity model. The newly added SBA is considerably complicated in terms of the different formats across the subjects. Given that the goals were initially unclear, various secondary schools determined precautionary measures to satisfy not only the stated objectives from EDB papers but also to settle the uncertainty along the implementation, such as time constraints, preparation, content, and topics.

Generalizing the decisions and policies with cultural and moral leadership is equally important. With the TWGH Headquarters mission, all secondary schools including KSKC should manifest the four virtues: diligence, frugality, loyalty, and trust, from their pedagogical ideologies. These four elements are particularly authentic to SEN/SpLD students. These elements should be fully nurtured with core values as versatile citizens instead of academic elites. Otherwise, the students would face unprecedented pressure to attain excellent results in public examinations.

Overall, the writer realizes that moral leadership is at root the most significant ideology to embody the leader's charisma, which is the most effective way to influence not only the teaching staff, but also the students, parents, and stakeholders ( $\mathrm{Yu}, 2002)$. A possible means to accomplish moral leadership is to prioritize role-modeling. In short, the principal should regard all stakeholders as individuals rather than parts of a machine.

\subsection{Triangulation method to evaluate the validity of the leadership}

The above comprehensive approach has provided a vague flow of management framework to cater to various situations anticipated in a special school such as KSKC under NSS reform. Nonetheless, the evaluation and validity of the principalship are more than essential when sustaining high-caliber management to accomplish the goals of the NSS educational reform (Bush, 2003, Tang, 2011; Yu, 2002). Bush suggests that a single model might be too general to investigate the efficacy of principalship. Research focusing on quantitative data may be challenged by the postmodern and subjective approach, such that numerical data can be trivialized by neglecting individual perceptions, whereas research stressing qualitative analysis could be criticized by formal and collegial managers who have neither concrete evidence nor empirical foundation. We can thus utilize a triangulated evaluative methodology derived from Bush (2003) to justify the validity of managerial skills and leadership models exercised by the principal. This method includes observations, surveys, and interviews.

\subsubsection{Observation}

As previously mentioned, the efficacy of learning and teaching is directly related to the prevalence of leadership and management skills. Salient leadership can cultivate promising teaching performance. Considering specific situations of KSKC, all committee and panel heads can compile a lesson observation form, which is concurrently based on the learning outcomes of the NSS curriculum and its adaptation for SEN/SpLD students. The middle 
managers and the seniors, as well as the principal, can use the form/checklist to justify teaching and to monitor whether leadership can effectively guide the teacher.

\subsubsection{Surveys}

An anonymous Likert-scaled survey comprising various dimensions of the principalship can be filled out by the frontline teachers to survey the repertoire of leadership that the principal demonstrates. Before its implementation, the teachers should understand the rationale of the survey, that is, to track the attributes of leadership elements relevant to school operations. After the survey, the principal should obtain a vague picture of the six different dimensions: formal, collegial, subjective, political, ambiguity, and cultural model. Through the lens of the six-angle chart, the principal can consider whether the repertoire of his leadership can fulfill the corresponding requirement of his school. All panel and committee heads, as well as the principal, can discuss the types of leadership that are particularly relevant and authentic to the needs in terms of their own prerequisite perception of the teams. The principalship can be deemed ineffective if a single or a narrow range of leaderships is demonstrated.

\subsection{Informal discussion with teaching staff}

Conversely, according to the subjective and postmodern features, individual perceptions should be highly valued and thus be considered the major elements catalyzing school output. Thus, the principal should arrange time slots to exchange thoughts and share opinions with the teaching staff in a casual setting. Such action is especially crucial for middle managers that serve as a bridge between the principal and frontline teachers under certain circumstances. The principal, at this point, should nurture his capacity to receive opposing views as advantages to fine-tune his leadership, instead of being hostile to teachers who disagree with school-based policies. The more receptive the principal can be, the more thorough the mirror can reflect. Catering to the need of every stakeholder is highly sophisticated but at the very least, their voices can be heard and their efforts acknowledged through positive encouragement and compliment.

\section{Conclusion}

Being one of the most difficult schools to handle, KSKC encountered a series of changes and educational reform within this decade. Such difficulties range from the transformation from a job vocation center to a grammar school, the immersion of HKCEE, and later on NSS educational reform. To survive the challenges brought on by the NSS educational reform, a consistently reliable and multiple-tasked leadership style has become significantly primitive in strengthening team spirit. The principalship demonstrated by Chow and $\mathrm{Ng}$ polarized at two ends: one focused on collegial, participative, and subjective leadership emphasizing individual perceptions, whereas the other focused on formal, managerial leadership prioritizing top-down cohesive control. This contrast is considerably profound to researchers and other principals in this field. With Bush's work, we can conclude that unidimensional leadership is insufficient for the complicated and dynamic educational systems striving for globalization through educational reform. Instead, such approach narrows the visions and 
capability of a school, which ultimately results in grievance, frustration, and failure to accomplish teamwork. In Principal Ng's case (2013), one-third of the teachers receded from their current positions, with some being the middle managers because of their dismay and ignorance. Such is a warning to a small school challenged by rigor and uncertainty. Moreover, such circumstance is a critical moment to refigure and transform the managerial style by adopting a wider range of leadership styles as suggested in the integrated approach. Although the beginning might be time-dependent and full of challenges, the dilemma can be further resolved as long as a repertoire of leadership styles is demonstrated. The school seniors and the principal should ensure effective method to monitor the validity of the utilized leadership style and fine-tune the overall directions accordingly for sustainable growth and development. The above suggestions might not solve all the structural dilemmas that KSKC is faced with, but may serve as a basis for possible solutions that might help mitigate the disappointments and frustrations affecting the teaching team of KSKC.

\section{References}

Burke, W. W. (2008). Organization change. Thousands Oaks (Calif.): Sage publ.

Bush, T. (2003). Theories of educational leadership and management: Sage.

Chan, W. (2010). A Review of Educational Reform-New Senior Secondary (NSS) Education in Hong Kong. International Education Studies, 3(4), 26. http://dx.doi.org/10.5539/ies.v3n4p26

Cheng, Y. C. (2009). Hong Kong educational reforms in the last decade: Reform syndrome and new developments. International Journal of Educational Management, 23(1), 65-86.

Cheung, A. C., \& Wong, P. M. (2011). Effects of school heads' and teachers' agreement with the curriculum reform on curriculum development progress and student learning in Hong Kong. International Journal of Educational Management, 25(5), 453-473.

Gronn, P., Bush, T., Bell, L., \& Middlewood, D. (2010). Where to next for educational leadership. The principles of educational leadership and management, 70-86.

Ho, D. C. W. (2010). Leadership for school improvement: Exploring factors and practices in the process of curriculum change. Early Education and Development, 21(2), 263-284. http://dx.doi.org/10.1080/10409280903582835

Jones, S., Lefoe, G., Harvey, M., \& Ryland, K. (2012). Distributed leadership: A collaborative framework for academics, executives and professionals in higher education. Journal of Higher Education Policy and Management, 34(1), 67-78. http://dx.doi.org/10.1080/1360080X.2012.642334

Leithwood, K., Harris, A., \& Hopkins, D. (2008). Seven strong claims about successful school leadership. School leadership and management, 28(1), 27-42. http://dx.doi.org/10.1080/13632430701800060 
Quong, T. (2011). An Analysis of Educational Reform at the School Level in Hong Kong.

Tang, S. Y. F. (2011). Teachers' professional identity, educational change and neo-liberal pressures on education in Hong Kong. Teacher Development, 15(3), 363-380. http://dx.doi.org/10.1080/13664530.2011.608518

Walker, A. (2004). Constitution and culture: Exploring the deep leadership structures of Hong Kong schools. Discourse: studies in the cultural politics of education, 25(1), 75-94. http://dx.doi.org/10.1080/0159630042000178491

Wong, M. L.-Y. (2009). Perspectives on the English Language Education of Hong Kong's New Senior Secondary (NSS) Curriculum. Professional Teaching Articles, 35, 1-27.

Yu, H. (2002). A shift in Hong Kong principals' leadership conceptions. Asia Pacific Education Review, 3(1), 37-47. http://dx.doi.org/10.1007/BF03024919

\section{Websites}

Tung Wah Group of Hospitals (TWGHs) Education Division: Retrieved from http://www.tungwah.org.hk/?content=293

Tung Wah Group of Hospitals (TWGHs) Education Services: Retrieved from http://www.tungwah.org.hk/?content $=410$

TWGHs Mr and Mrs Kwong Sik Kwan College: Retrieved from

http://www.twghsksk.edu.hk/

\section{Copyright Disclaimer}

Copyright for this article is retained by the author(s), with first publication rights granted to the journal.

This is an open-access article distributed under the terms and conditions of the Creative Commons Attribution license (http://creativecommons.org/licenses/by/3.0/). 